\title{
Human NRDRB1, an Alternatively Spliced Isoform of NADP(H)-Dependent Retinol Dehydrogenase/Reductase Enhanced Enzymatic Activity of Benzil
}

\author{
Yinxia Yan Xuhong Song Gefei Liu Zhongjing Su Yongming Du Xuxia Sui \\ Xiaolan Chang Dongyang Huang \\ Department of Cell Biology, Shantou University Medical College, Shantou Guangdong, China
}

\section{Key Words}

NRDRB1 • Alternative splicing • Dicarbonyl reductase $\bullet$ Benzil $\bullet$ Metabolism of xenobiotics

\begin{abstract}
Aims: Human NRDRB1, a 226 amino acid alternatively spliced isoform of the NADP(H)dependent retinol dehydrogenase/reductase (NRDR), lacks the complete coding region of exon 3 , but preserves all the important functional motifs for NRDR catalytic activity. Nevertheless, its tissue distribution and physiological function remain to be elucidated. Methods: Expression of NRDRB1 and NRDR in cells and tissues was analyzed by semi-quantitative polymerase chain reaction (PCR) and western blot. NRDRB1 was expressed as a $\mathrm{His}_{6}$ fusion protein and subjected to kinetics assays. Results: Recombinant NRDRB1 had 1.2 to 8.6 fold higher $\mathrm{k}_{\mathrm{cat}} / \mathrm{K}_{\mathrm{m}}$ values than recombinant NRDR, depending on the substrate. NRDRB1 catalyzed the NADPHdependent reduction of $\alpha$-dicarbonyl compounds, such as isatin, 9,10-phenanthrenequinone, and especially benzil. The significantly high catalytic activity and the relatively high expression in human liver of NRDRB1 conferred cellular resistance to benzil-induced cell toxicity and over-expression of NRDRB1 in low expressing Ec109 cells significantly enhanced cell tolerance toward benzil. Conclusions: Based on its substrate specificity, catalytic activity and relatively high expression in human liver tissue, our results suggest that NRDRB1, an alternatively spliced isoform of NRDR in vivo functions better than NRDR as a dicarbonyl reductase for xenobiotics containing reactive carbonyls. Our study is the first reporting this phenomenon of the enzymes involved in biochemical reactions.
\end{abstract}




\section{Cellular Physiology Cell Physiol Biochem 2012;30:1371-1382 \begin{tabular}{l|l|l|}
\hline DOI: 10.1159/000343326 & O 2012 S. Karger AG, Basel \\
\hline
\end{tabular} and Biochemistry $\frac{\text { Published online: November }}{\text { Yan/Song/Liu et al.: Enhanced Enzymatic Activity of Alternatively Spliced Enzyme }}$}

\section{Introduction}

The short-chain dehydrogenase/reductase (SDR) superfamily comprises a large and diverse group of genes with members found in all organisms. Members of this family are mainly oligomeric enzymes with subunits of about 250-350 amino acid residues. SDR members share distinct sequence motifs comprising conserved nucleotide cofactor and active site residues [1-3], with a typical overall residue identity of 15-30\%. Accordingly, SDR enzymes are mostly NAD(P)(H)-dependent dehydrogenases/reductases, acting on a heterogeneous set of substrates, including steroids, retinoids, prostaglandins, sugars and xenobiotics. NADP(H)-dependent retinol dehydrogenase/reductase (NRDR) encoded by the DHRS4 gene is a member of SDR superfamily. We identified the NRDR protein in the cytosol of rabbit liver tissue and found it to harbor strong retinol oxidation and retinal reduction activity [4]. NRDR has subsequently been found to play a special role in the retinoic acid metabolism of animals, such as mouse, pig, and dog [5-7].

Human NRDR is encoded by the DHRS4 gene within the DHRS4 gene cluster along with its two immediately downstream homologous genes, DHRS4L2 and DHRS4L1 generated by gene duplication. The DHRS4 gene contains 8 exons encoding two possible variants of human NRDR, containing 278 amino acids and 260 amino acids due to use of alternative translation initiation sites. In our previous study without $\mathrm{N}$-terminal sequencing analysis of human NRDR, translation of human NRDR was assumed to start at the first initiation site, theoretically encoding a $29.5 \mathrm{kDa}$ protein of 278 amino acids [8]. However, our recent studies (unpublished) provide indication that a second initiation site is likely to be the start of translation of the NRDR protein, leading to a $27.3 \mathrm{kDa}$ mature protein with 260 amino acids. Various alternatively spliced variants of NRDR exist in normal human tissues and tumor cell lines [8-12]. Alternative splicing is a key phenomenon that contributes to the production of different mature transcripts from the same primary RNA sequence [13]. New high throughput sequencing technology has revealed that alternative splicing is evident in over $90 \%$ of human genes [14]. Currently, 30 differentially-spliced transcripts and concomitantly 30 different NRDR translation products are predicted by NCBI. However, only two isoforms of human NRDR have been detected, namely NRDRB1 [8] and NRDRA2 [12]. The 226-amino acid NRDRB1 lacking the complete coding region of exon 3 was originally identified in human cervical squamous carcinoma. At present, we found NRDRB1 to be predominantly expressed in human hepatocyte cells.

Although alternative splicing seems to be a widespread phenomenon in the human transcriptome, the in vivo functions of protein isoforms generated by alternative splicing remain poorly defined in the majority of cases. To date, little is known about the expression pattern and physiological role of NRDRB1. In this study, we generated prokaryotic and eukaryotic NRDRB1 and NRDR expression systems to determine protein biochemical activity and physiological function. Several steroids and xenobiotic $\alpha$-dicarbonyl compounds, including benzil, were chosen as substrates in order to reveal the physiological function of NRDRB1 and give insight into the effect of alternative splicing on NRDR protein function.

\section{Materials and Methods}

Cell culture and human liver tissue samples

The following human cell lines were used: Hela cervical carcinoma cells, Ec109 esophageal carcinoma cells, HL7702 normal hepatocyte cells, HepG2 hepatocarcinoma cells, SKOV3 ovarian adenocarcinoma cells, A549 lung adenocarcinoma cells, HEK293 embryonic kidney cells and HS181.TES testis cells. All were obtained from the Cell Bank of Chinese Academy of Sciences (Shanghai, China), and were maintained in RPMI-1640 medium supplemented with $10 \%$ fetal bovine serum, at $37^{\circ} \mathrm{C}$ in a humidified atmosphere with $5 \% \mathrm{CO}_{2}$.

Histopathologically confirmed human normal liver tissues were obtained from four male patients, 3545 years of age, hospitalized for cholecystitis and who underwent cholecystectomy at Shantou University 
Table 1. Primers used in the present study

\begin{tabular}{llll}
\hline Primer Name & Sequence $\left(5^{\prime}\right.$-3') & Gene & Use \\
\hline NRDRF & TCC ACC GAC GGG ATC GGC TT & NRDR & Semi qPCR \\
NRDRR & ATG CCA GCA CAA TCC TCT GGC & & \\
NRDRB1F & TGG CCA CGA CTC TGG ACA TTA & NRDRB1 & Semi qPCR \\
NRDRB1R & CCT TCT TAT CCG CAG GGT TTC & & \\
ACBTF & TGA CGT GGA CAT CCG CAA AG & 3-actin & Semi qPCR \\
ACBFR & CTG GAA GGT GGA CAG GGA GG & & \\
plVEXF & CATG CCATGG ATG GCC AGC TCC GGG ATG & NRDR/NRDRB1 & RTS \\
plVEXR & CCG CTCGAG TCA GAG GCG GGA CGG GGT TC & & \\
Seq F & TAA TAC GAC TCA CTA TAG & NRDR/NRDRB1 & Sequencing \\
Seq R & TTT CCA TTC GCC ATT CAG G & & \\
\hline
\end{tabular}

Affiliated Hospital. The study protocol was approved by the Human Ethics Review Committee of Shantou University, and a signed consent form was obtained from each subject. Tissue samples were immediately frozen in liquid nitrogen and stored in a $-80^{\circ} \mathrm{C}$ freezer until analysis.

\section{Semi-quantitative PCR and western blot}

The expression of NRDRB1 and NRDR in cells and tissues was analyzed by semi-quantitative polymerase chain reaction (PCR) and western blot analysis. Semi-quantitative PCR was used on mRNA isolated from 8 different cell lines and 4 different human liver tissue samples. PCR products were subjected to electrophoresis on a 1.2\% agarose gel. Primers for specific amplifications are shown in Table 1. Rabbit antiNRDR polyclonal antibody $[9,15]$ and goat anti-rabbit IgG conjugated to horseradish peroxidase $(1: 3,000$, Pierce) were used in the western blot analysis. SDS-PAGE gels were stained with Coomassie Brilliant Blue to confirm the size of the targeted protein.

RNA extraction, RT-PCR and 3' and 5' RACE assay

Total RNA was extracted from the HL7702 cell line using the RNeasy Mini Kit (Qiagen, Hilden, Germany). RNA (1 $\mu \mathrm{g})$ from each sample was reverse-transcribed into cDNA using a 2-strand cDNA synthesis kit (Promega, Madison, WI). NRDR and NRDRB1 were cloned by PCR using two sets of primers: NRDRF and NRDRR, and NRDRB1F and NRDRB1R. Subsequently, for NRDRB1, 3'RACE and 5'RACE were performed to obtain the full-length cDNA using the protocol supplied by the manufacturer (Invitrogen, San Diego, CA), but slightly modified to use nested PCR. The PCR products were analyzed by electrophoresis on a $1.2 \%$ agarose gel, and the corresponding PCR products were gel-purified and cloned into the pGEM-T vector (Promega). Positive clones were sequenced by the dideoxynucleotide method.

Expression and purification of NRDRB1 and NRDR in E. coli

NRDRB1 and NRDR cDNA were cloned into pDEST17 bacterial expression vectors (Gateway Expression system, Invitrogen) to express the proteins with His-tag sequences. The constructs were transformed into E. coli BL21-AI cells (Takara, Japan), and the open reading frame of the cDNA in the expression plasmid was verified by sequencing.

Overexpression of recombinant protein was induced at mid-log growth phase of BL21-AI using $0.2 \%$ L-arabinose at $25^{\circ} \mathrm{C}$. The expressed NRDRB1 and NRDR protein was purified using affinity chromatography, as described previously [4]. The purified enzymes showed single protein bands on SDS-PAGE analysis. Typical yields for both proteins were $2-5 \mathrm{mg} / \mathrm{L}$ of culture, as measured by the BCA method.

\section{Kinetic assays}

The reductase activity of recombinant enzymes was determined at $25^{\circ} \mathrm{C}$ by measuring the rate of change in NADPH absorbance at $340 \mathrm{~nm}$. The standard reaction mixture consisted of $0.1 \mathrm{M}$ potassium phosphate, $\mathrm{pH}$ 6.5, $0.1 \mathrm{mM} \mathrm{NADPH}, 1 \mathrm{mM}$ substrate, and enzyme in a total volume of $1.0 \mathrm{ml}$. The apparent $\mathrm{K}_{\mathrm{m}}$ and $\mathrm{k}_{\text {cat }}$ values were determined over a range of eight substrate concentrations at a saturating concentration of coenzyme NADPH by fitting the initial velocities to the Michaelis-Menten equation, and are expressed as the means of three determinations. 


\section{Cellular Physiology Cell Physiol Biochem 2012;30:1371-1382

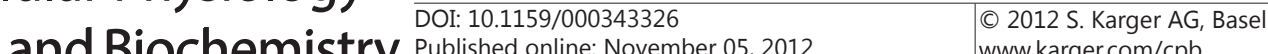 and Biochemistry Published online: November 05, 2012, www.karger.com/cpb}

Expression of NRDRB1 and NRDR proteins using the Wheat Germ in vitro Rapid Translation System (RTS)

Plasmids (pGEM-T Easy vector; Promega) encoding NRDR or NRDRB1 cDNA and primer set pIVEXF and pIVEXR were used to amplify the sequence of the NRDR and NRDRB1 regions. PCR conditions with Taq polymerase: initial denaturation for $3 \mathrm{~min}$ at $94^{\circ} \mathrm{C}, 25$ cycles of $1 \mathrm{~min}$ denaturation at $94^{\circ} \mathrm{C}, 1 \mathrm{~min}$ annealing at $58^{\circ} \mathrm{C}$, elongation for $2 \mathrm{~min}$ at $72^{\circ} \mathrm{C}$ and a final elongation step of $8 \mathrm{~min}$ in $50 \mu \mathrm{l} \mathrm{reaction}$ mixture containing $25 \mu \mathrm{l} 2 \times \mathrm{PCR}$ mix, $1 \mathrm{ul}$ of a $10 \mu \mathrm{mol} / \mathrm{L}$ solution of each primer, $4 \mu \mathrm{l}$ DNA as template, and $19 \mu \mathrm{l}$ distilled water. PCR products were subjected to electrophoresis on a $1.2 \%$ agarose gel and purified with the Gel Extraction Kit. Purified DNA was ligated into the pIVEX1.3 vector using the Nco I and Xho I restriction endonucleases (New England Biolabs, Frankfurt am Main, Germany). All DNA was verified by sequencing using the sequencing primer set SeqF and SeqR. Protein synthesis reactions were conducted following the manufacturer's protocol (Roche, Basel, Switzerland). Protein samples were subjected to western blotting using rabbit anti-human NRDR antibody as described above.

Transfection and over-expression of NRDRB1 and NRDR in HEK293 cells

HEK293 cells were inoculated into 100-mm Petri dishes $\left(3 \times 10^{6}\right.$ cells /dish) and transfected with 8 $\mu \mathrm{g}$ plasmid DNA, subcloned into the pcDNA3.0 mammalian expression vector using Polyfect transfection reagent (Qiagen, Hilden, Germany). Control cells were transfected with an equal amount of the parental vector alone. After $24 \mathrm{~h}$ post-transfection, cells were harvested with a rubber scraper, collected by low speed centrifugation, and then resuspended in hypotonic buffer $(10 \mathrm{mM}$ potassium phosphate buffer, $\mathrm{pH}$ 7.4, containing $1 \mathrm{mM}$ phenylmethylsulfonyl fluoride), put on ice for $20 \mathrm{~min}$, and finally homogenized using a Dounce homogenizer.

Catalytic activity of NRDRB1 and NRDR for benzil by HPLC

Benzil $(2 \mathrm{mM})$ was reduced in the assay mixture containing each protein sample $(10-20 \mu \mathrm{g})$ obtained above, $500 \mu \mathrm{M}$ NADPH and $0.1 \mathrm{M}$ potassium phosphate, $\mathrm{pH} 6.5$, and incubation at $37^{\circ} \mathrm{C}$ for $4 \mathrm{~h}$, then the reaction mixture was extracted with ethyl acetate, evaporated and purified by silica gel column chromatography [16]. All previous steps were done in the dark under minimal red light illumination. The products were analyzed using an HP1090 high-pressure liquid chromatography system (Hewlett-Packard). The stationary phase was a reverse-phase C18 column (Waters Symmetry, $4.6 \mathrm{~mm} \times 150 \mathrm{~mm}$ ). The mobile phase was made up of $60 \%$ acetonitrile and $40 \% 0.1 \mathrm{M}$ potassium phosphate at $\mathrm{pH} 6.5(\mathrm{v} / \mathrm{v})$. The flow rate was $1 \mathrm{ml} / \mathrm{min}$, and analysis was simultaneously monitored at $254 \mathrm{~nm}$.

Analysis of benzil-induced cell toxicity and detoxification for NRDRB1

Eight cell lines were plated into a 96 -well plate at a density of $1 \times 10^{5}$ cells/well in medium containing $2 \%$ FBS and allowed to attach for $24 \mathrm{~h}$. The following day, benzil was added for $24 \mathrm{~h}$, then cell viability was evaluated by the trypan blue dye exclusion method, and expressed as \% of control culture conditions as described previously [17]. To examine the relationship between cell viability and expression of NRDRB1, Ec109 cells were transfected with NRDR and NRDRB1. Transfected cells were maintained in medium containing 2\% FBS for $24 \mathrm{~h}$, then exposed to various concentrations of benzil for an additional $24 \mathrm{~h}$. Cell viability was evaluated by trypan blue exclusion. Cell collection and preparation of the cell extracts were performed and probed for NRDRB1 and NRDR by western blotting.

\section{Results}

\section{Functional analysis of human NRDRB1}

According to the NCBI database, DHRS4 is present in a wide range of living species from bacteria to humans. Ubiquitous expression in several tissues [18] and high conservation of NRDR in Homo sapiens, Mus musculus and Xenopus laevis suggest a basic metabolic role for NRDR. The typical features of enzymes of this family (Fig. 1), active site motifs and conserved amino acid residues follow the classical SDR pattern, and are present in NRDRB1 (containing the A84-K118 deletion from NRDR).

$6 \times$ His-tagged NRDRB1 and NRDR could be clearly separated on the SDS-PAGE gel (Fig. 3a) [8]. NRDR and NRDRB1 showed an expected clear separation with the apparent 


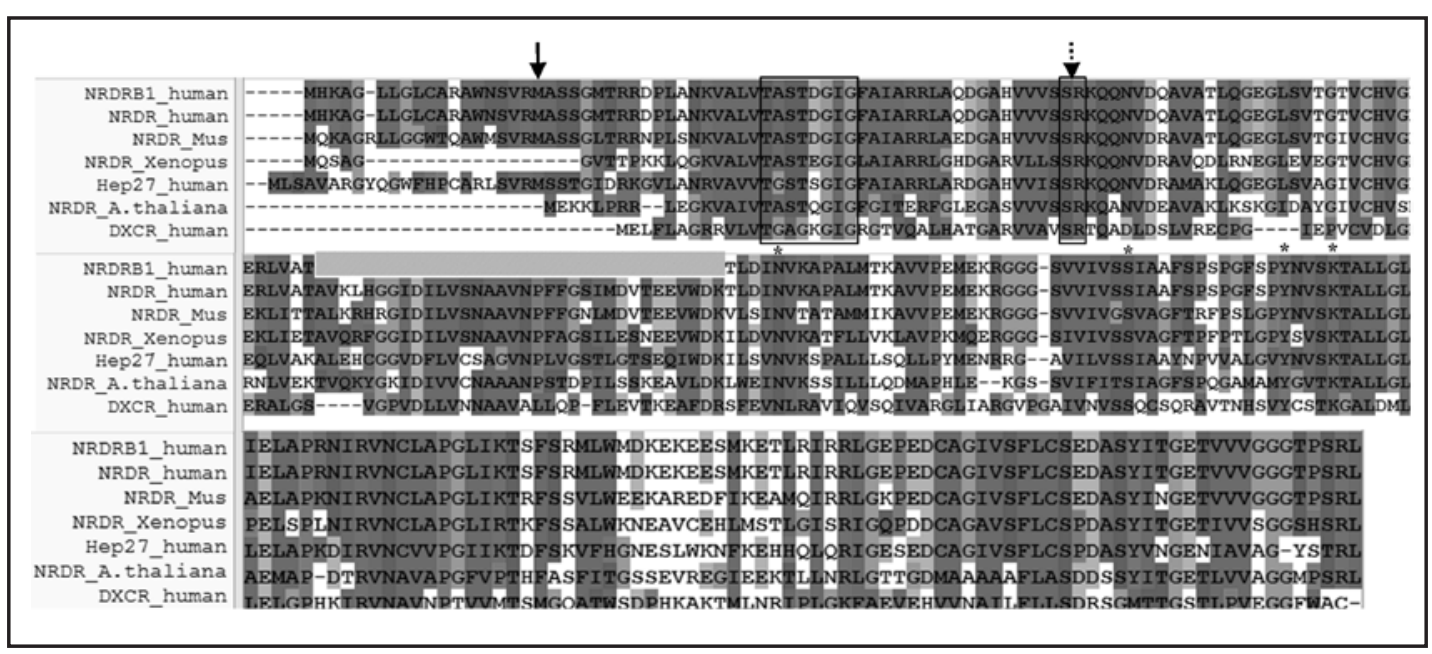

Fig. 1. Sequence alignment of human NRDRB1 and related SDR enzymes. An alignment comparing NRDRB1 (GI: 84688723) to the full-length proteins NRDR from human (GI: 32483357), mouse (NRDR_Mus) (GI: 13097510), Xenopus laevis (NRDR_Xenopus) (GI: 148222765), and Arabidopsis thaliana (NRDR_Xenopus) (GI: 18412959) was generated in the Clustal X program. For comparison, human Hep27 (GI: 5031737) and human DCXR (GI: 7705925) are included. The 34-amino acid sequence, from A84 to K118 deleted in NRDRB1, is shaded in gray. Boxing indicates the sequence motif for cofactor binding found in SDR enzymes. Asterisks above the sequence denote four essential residues that compose the catalytic tetrad characteristic of SDR proteins. The solid arrow points to the mature N-terminus as observed from sequence analysis of NRDRB1, also used for recombinant expression in E. coli. The dashed arrow indicates residues important for cofactor specificity. $\mathrm{NAD}(\mathrm{H})$ specificity is determined by an acidic residue, whereas NAD(P)(H)-dependent enzymes have no acidic residue at this position.

molecular weight on SDS-PAGE at $28 \mathrm{kDa}$ and $25 \mathrm{kDa}$, respectively, in accordance with the theoretical mass of $27.5 \mathrm{kDa}$ and $23.9 \mathrm{kDa}$.

\section{Expression analysis of NRDRB1 in human cell lines and liver tissue}

The expression of NRDR and NRDRB1 at both the mRNA and protein levels are shown in Fig. 2.

Unlike NRDR, which was ubiquitously expressed in all cell lines tested and human liver tissue, relatively high NRDRB1 expression was only detected in human liver tissue and human hepatic cells, even though there was also slight expression of NRDRB1 in both SKOV3 and Hela cell lines (Fig. 2a). Although NRDRB1 was never dramatically overexpressed when compared to the levels of NRDR, it was expressed at relatively high levels in human liver tissue and hepatic cells when compared with other cell lines tested in this study. Both the full-length NRDR and the NRDRB1 isoform were predominately expressed in human normal liver tissues (Fig. 2b). It should be noted that NRDRB1 mRNA was expressed at higher levels than NRDR mRNA in human liver tissues, though the protein expression of NRDRB1 was not dominant. This is not unexpected because the relation between mRNA and protein is not strictly linear, but has a more intrinsic and complex dependence [19].

\section{Enzyme kinetics of NRDRB1 and NRDR}

Kinetic constants for NRDRB1-mediated carbonyl reduction were performed by measuring the change in absorbance at $340 \mathrm{~nm}$ of eight substrate concentrations at a saturating concentration of coenzyme in the reaction. The kinetic constants of NRDRB1 and NRDR toward $\alpha$-dicarbonyl compounds and 3-ketosteroids are shown in Table 2 . We found that human NRDRB1 converts $\alpha$-dicarbonyl compounds, such as benzil, 9,10-phenanthrenequinone and isatin, in an NADPH dependent manner (data not shown). NRDRB1 had a higher $\mathrm{k}_{\text {cat }}$ value and lower $\mathrm{K}_{\mathrm{m}}$ value, and exhibited 1.2-fold (1-phenylisatin) 


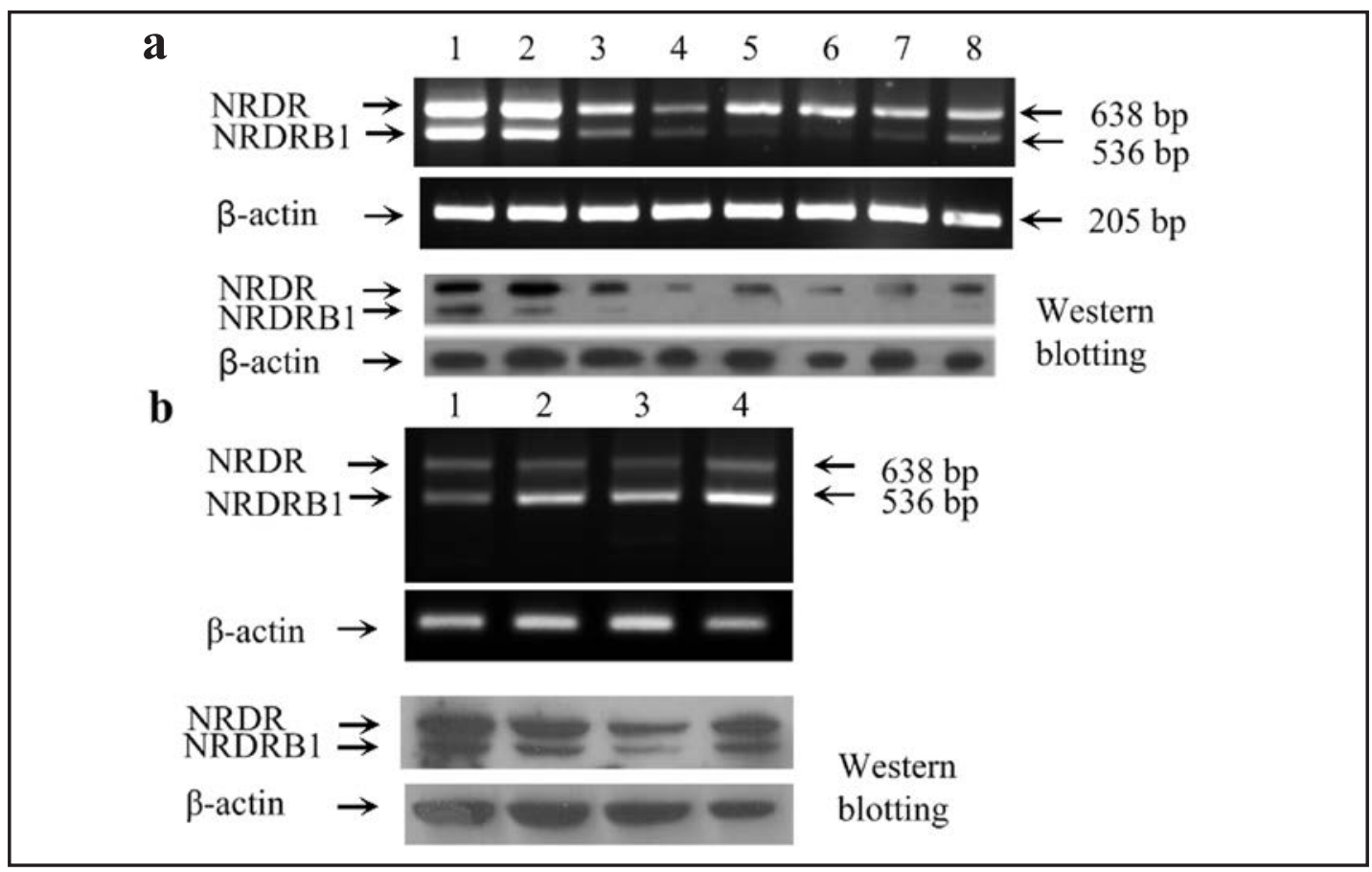

Fig. 2. Tissue distribution of human NRDRB1 and NRDR. mRNAs and proteins were detected by specific reverse transcription-polymerase chain reaction (RT-PCR) and western blotting followed by 12\% SDS-PAGE. Agarose gel electrophoresis identifying NRDRB1 (amplified with primers NRDRB1F and NRDRB1R) and NRDR (amplified with primers NRDRF and NRDRR). As a loading control, $\beta$-actin primers were used. Cell and liver tissue extracts were subjected to western blotting using rabbit anti-human NRDR antibody. (a) Cells: 1, HL7702; 2, HepG2; 3, SKOV3; 4, Ec109; 5, HS181.TES; 6, HEK293; 7, A549; 8, Hela. Expression of NRDR and NRDRB1 mRNA and protein in four different liver tissue samples are shown in (b).

to 8.6-fold (benzil) higher catalytic efficiencies $\left(\mathrm{k}_{\mathrm{cat}} / \mathrm{K}_{\mathrm{m}}\right)$ than NRDR towards the four substrates (Table 2). The $\mathrm{k}_{\text {cat }} / \mathrm{K}_{\mathrm{m}}$ value measured for $5 \beta$-pregnane-3, 20-dione was in the same range for NRDR and NRDRB1. However, NRDR and NRDRB1 were not very active towards $5 \beta$-androstan-17 $\beta$-ol-3-one in our study (Table 2 ). This is in contrast to a prior study that reported a $\mathrm{K}_{\mathrm{m}}$ value in the low micromolar range [20].

\section{NRDRB1 has a higher catalytic activity for benzil than NRDR}

We expressed human NRDRB1 and NRDR both in HEK293 cells and in an in vitro translation system (RTS) and conducted HPLC analysis. Western blot analysis confirmed high-level over-expression of proteins in HEK293 cells versus low protein expression in the control cells transfected with the vector alone (Fig. 3b). NRDRB1 and NRDR were also expressed successfully by in vitro translation system (Fig. 3c). Both NRDR and NRDRB1 could reduce benzil to benzoin, but a lesser amount of benzoin was detected in the reaction products of NRDR than NRDRB1 (Fig. 4). In NRDRB1 reactions using benzil as a substrate, only benzoin could be detected. These results are consistent with our kinetics measurements using 340-nm spectrophotometric analysis. NRDRB1 has a higher catalytic activity than NRDR for benzil.

\section{NRDRB1 is involved in benzil detoxification}

The viability of cell lines decreased in a dose-dependent manner after treatment with benzil for 24 h over a benzil concentration range from 0 to $20 \mu \mathrm{M}$ (Fig. 5a). Cell lines displayed a range of sensitivities. For example, at $5 \mu \mathrm{M}$ benzil, viability was $96 \%$ for HL7702 cells but $33 \%$ for Ec109 cells, consistent with the high NRDR/NRDRB1 expression in HL7702 cells 
Table 2. Kinetic constants of NRDRB1 and NRDR towards dicarbonyl compounds and steroids. The Reductase activities were assayed at $\mathrm{pH}$ 6.0, except for substrates shown with an asterisk, which were measured at $\mathrm{pH}$ 7.4. The standard errors of the values were less than $15 \% . \mathrm{K}_{\mathrm{m}}$ values are given in $10^{-6} \mathrm{M}, \mathrm{k}_{\mathrm{cat}}$ values are given in $\mathrm{min}^{-1}$ and $\mathrm{k}_{\text {cat }} / \mathrm{K}_{\mathrm{m}}$ values are given in $\mathrm{min}^{-1} \mu \mathrm{M}^{-1}$. Values shown are the average of three to five experiments. The kinetic constants for the substrates were determined with $100 \mu \mathrm{M}$ NADPH.

\begin{tabular}{|c|c|c|c|c|c|c|}
\hline \multirow[b]{2}{*}{ Substrate } & \multicolumn{3}{|c|}{ NRDRB1 } & \multicolumn{3}{|c|}{ NRDR } \\
\hline & $\begin{array}{l}\mathrm{K}_{\mathrm{m}} \\
(\mu \mathrm{M})\end{array}$ & $\begin{array}{l}\text { Kat } \\
\left(\min ^{-1}\right)\end{array}$ & $\begin{array}{l}\mathrm{K}_{\text {cat }} / \mathrm{K}_{\mathrm{m}} \\
\left(\mathrm{min}^{-1} \mu \mathrm{M}^{-1}\right)\end{array}$ & $\begin{array}{l}\mathrm{K}_{\mathrm{m}} \\
(\mu \mathrm{M})\end{array}$ & $\begin{array}{l}\text { kat } \\
\left(\min ^{-1}\right)\end{array}$ & $\begin{array}{l}\mathrm{k}_{\mathrm{cat}} / \mathrm{K}_{\mathrm{m}} \\
\left(\mathrm{min}^{-1} \mu \mathrm{M}^{-1}\right)\end{array}$ \\
\hline Benzil & 1.8 & 3600 & 2045 & 7.1 & 1690 & 237 \\
\hline 9,10-Phenanthrenequinone & 2.2 & 737 & 335 & 3.4 & 720 & 212 \\
\hline Isatin & 475 & 3370 & 7.09 & 389 & 1520 & 4.00 \\
\hline 1-Phenyisatin & 18.8 & 2570 & 137 & 12.8 & 1500 & 117 \\
\hline Menadione & 7.5 & 27.1 & 3.64 & 29.7 & 31.4 & 1.06 \\
\hline $5 \beta$-Pregnane-3,20-dione ${ }^{*}$ & 5.1 & 3.4 & 0.67 & 4.6 & 3.6 & 0.78 \\
\hline $5 \beta$-Androstan-17 $\beta$-ol-3-one & 127.8 & 11.8 & 0.09 & 117 & 12.6 & 0.11 \\
\hline
\end{tabular}

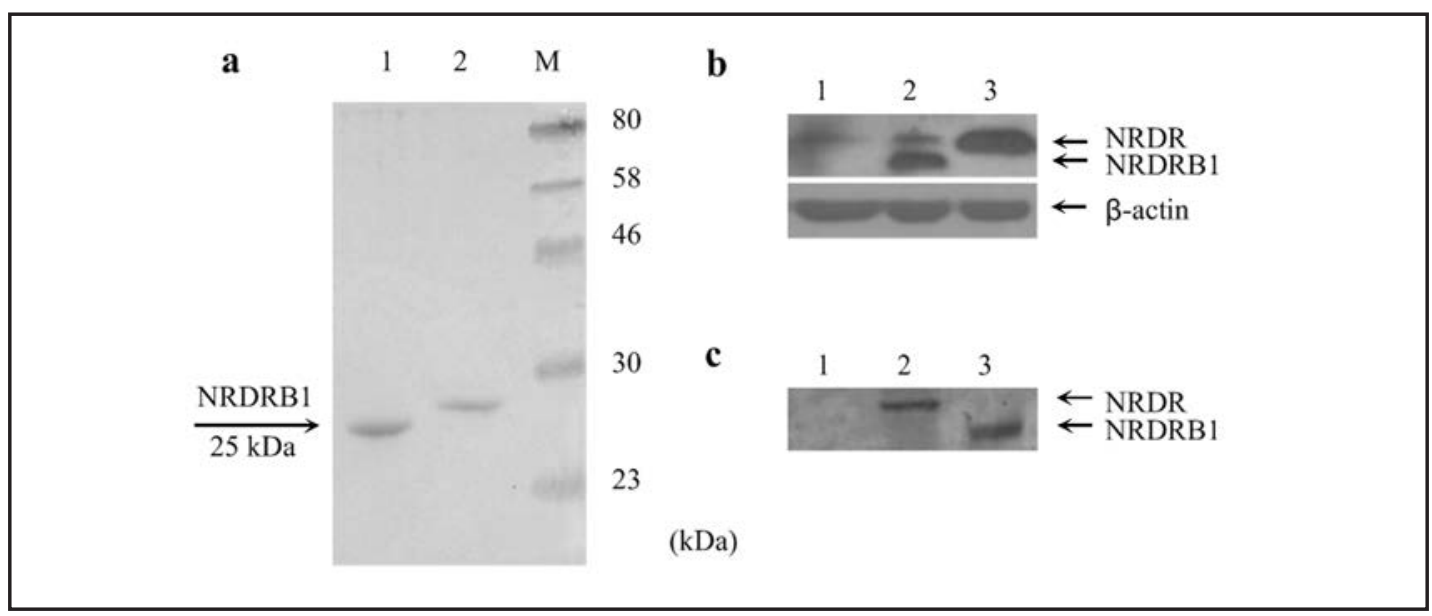

Fig. 3. Purification of recombinant proteins and Western blotting analysis. (a) SDS-PAGE of purified recombinant NRDRB1 and NRDR. The amounts of the purified enzymes analyzed were $2 \mu \mathrm{g}$ in $12 \%$ SDSPAGE. Proteins were stained with 0.2\% Coomassie Brilliant Blue R-250. Lanes: 1, NRDRB1; 2, NRDR. (b) HEK293 cells were transfected with expression plasmids encoding human NRDRB1 and NRDR. Transfection of empty vector was used as a negative control. After $24 \mathrm{~h}$, cell lysates were prepared and probed for NRDRB1 and NRDR by western blotting. Lanes: 1, negative control; 2, NRDRB1; 3, NRDR. (c) Western blotting analysis of His $_{6}$-tagged proteins in RTS. Proteins synthesized in the cell-free protein expression system were analyzed for NRDRB1 and NRDR by western blotting. Lanes: 1, negative control; 2, NRDR; 3, NRDRB1.

and low NRDR/NRDRB1 expression in Ec109 cells. We tested whether NRDRB1 could confer resistance to benzil-induced toxicity by over-expressing NRDRB1 in Ec109 cells. The viability of the control cells decreased in a dose-dependent manner after treatment with benzil for 24 h, but less benzil cytotoxicity was observed in the transfected cells (Fig. 5b). These results indicate that NRDRB1 can detoxify benzil in vivo. 


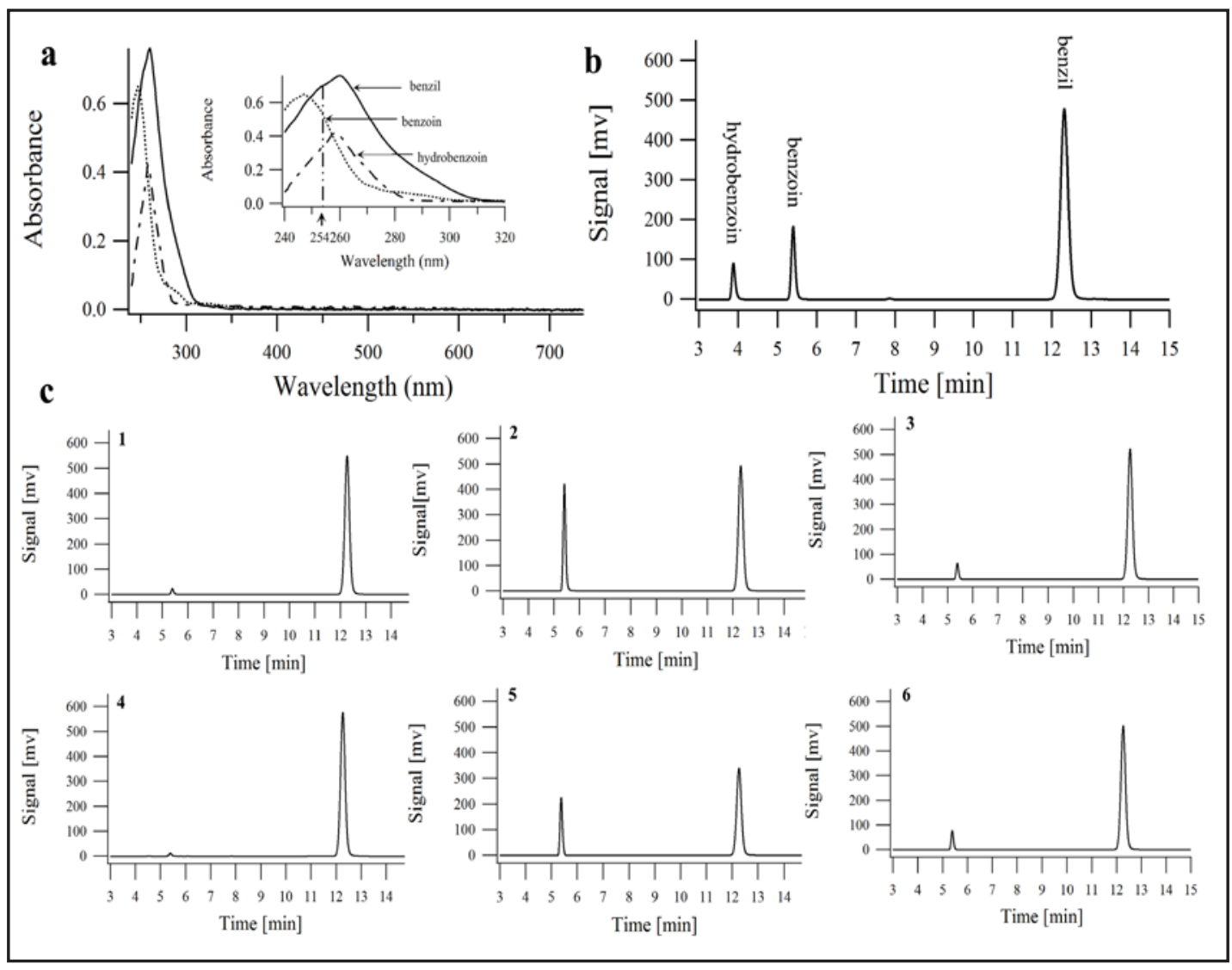

Fig. 4. HPLC analysis of catalytic activity of NRDRB1 and NRDR for benzil. (a) Wavelength-scan of standards by UV/VIS spectrophotometry. (b) Standards for benzil, benzoin and hydrobenzoin. Retention times are $12.32 \mathrm{~min}, 5.48 \mathrm{~min}$, and $3.84 \mathrm{~min}$, respectively. (c) HPLC analysis of recombinant NRDRB1 and NRDR towards benzil. HEK293 cells were transfected with expression vector harboring the cDNA for NRDRB1 or NRDR, or the vector alone. Benzil reductase activity of control plasmid, NRDRB1, and NRDR overexpressed in HEK293 cells is shown in (1), (2), and (3), respectively. (4)-(6) indicate the benzil reductase activity of the negative control, NRDRB1, and NRDR expressed by in vitro translation system.

\section{Discussion}

The expression pattern of NRDRB1 characterized in this report indicates that, similar to NRDR, NRDRB1, an alternatively spliced isoform of NRDR, exists not only in human cervical squamous carcinoma and Hela cell line, but also in human liver tissue and several other cell lines, e.g. the HL7702, HepG2, and SKOV3 cell lines. In addition, NRDRB1 was predominantly expressed in human liver tissue.

Although there is a 34-amino acid deletion in NRDRB1 due to alternative splicing, the common TGxxxGxG sequence motif for binding of coenzyme and the catalytic YxxxK sequence motif shared by the SDR superfamily are preserved (Fig. 1). Homologues of NRDR from humans and other animals have been shown to be active on an overlapping spectrum of carbonyl substrates [4, 5, 21-25], including steroids, retinoids, prostaglandins, sugars, and xenobiotics. The missing amino acid fragment in NRDRB1 is encoded by the third exon and does not belong to any known functional region. Thus we predicted that the deletion should not affect the catalytic character of the enzyme.

Enzymatic assay unequivocally indicates that both NRDR and NRDRB1 exhibit high catalytic activity on xenobiotic $\alpha$-dicarbonyl compounds, consistent with previous findings $[20,25]$. However, NRDRB1 shows significantly higher activity towards these substrates 


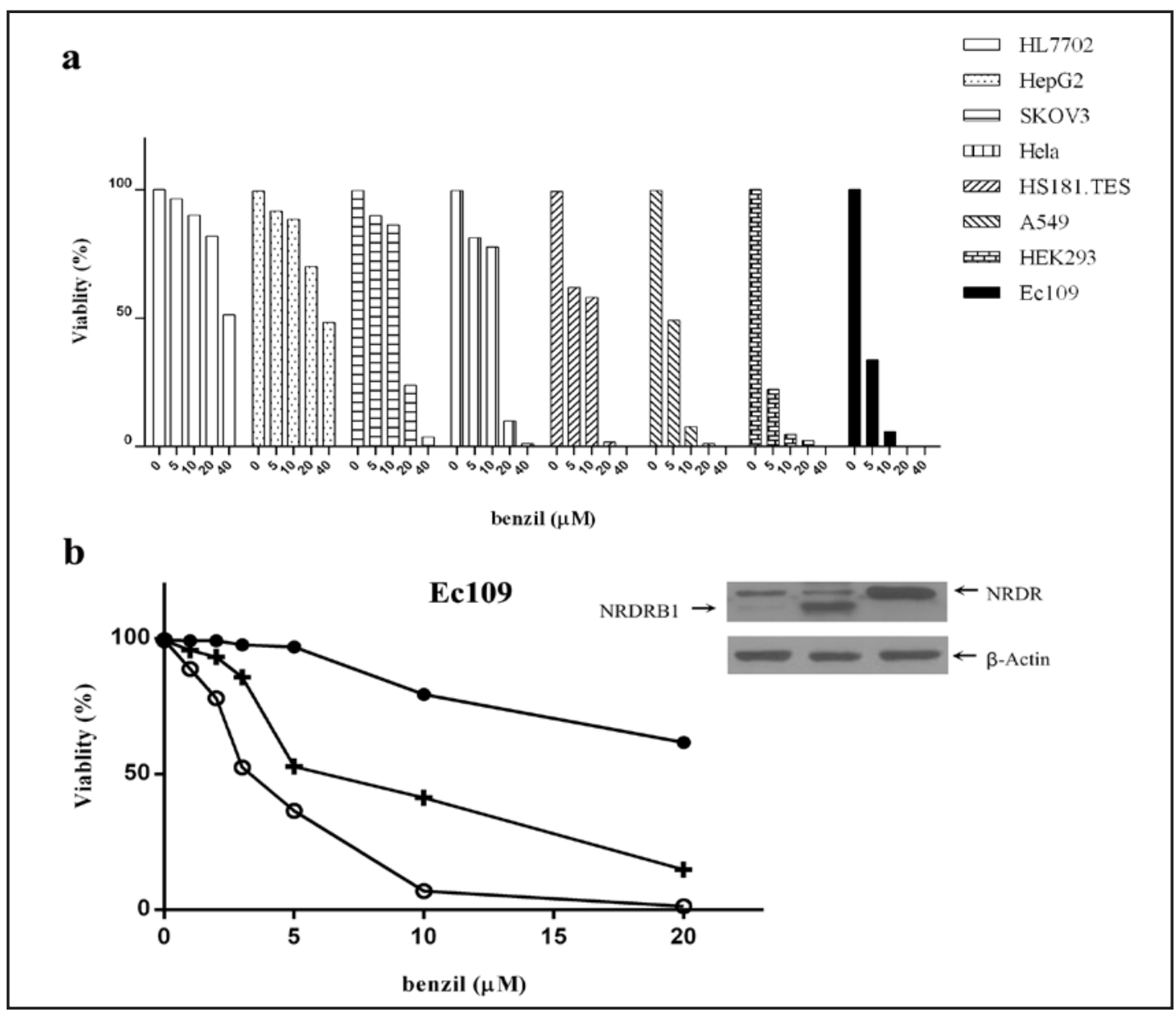

Fig. 5. NRDRB1 is involved in benzil-induced detoxification. (a) Benzil-induced cytotoxicity of different cells. Cells were cultured for $24 \mathrm{~h}$ with various concentrations of benzil. Cell viability is expressed as \% of control culture conditions that were treated with vehicle (dimethyl sulfoxide). (b) Effects of NRDRB1 overexpression on benzil-induced cytotoxicity of Ec109 cells. Cells were transfected with the expression vector encoding NRDR (cross), NRDRB1 (closed circles), or empty vector (open circles), and treated for 24 $\mathrm{h}$ with various concentrations of benzil. Ec109 cells transfected with empty vector or expression plasmids coding for human NRDRB1 and NRDR were harvested after cultured $24 \mathrm{~h}$ post-transfection. Western blot of whole cell lysates is shown in the upper right of (b).

compared with NRDR. The region lost in NRDRB1 is located outside the functional motif of the protein, and we predict the fragment lost in NRDRB1 shortens the distance between the coenzyme binding site and the substrate binding site, facilitating the interaction of the two active sites. According to the enzyme kinetics of NRDRB1 and NRDR, the $\mathrm{K}_{\mathrm{m}}$ and $\mathrm{k}_{\text {cat }}$ values for $5 \beta$-pregnane-3, 20-dione metabolism are comparable to that of AKR1C1, which is considered a very efficient enzyme for reduction of 3-ketosteroids [26]. Therefore, in addition to AKR1C1, NRDR and NRDRB1 may also physiologically act as 3-ketosteroid reductase that convert $5 \beta$-pregnane-3, 20-dione to $5 \beta$-pregnan-3 $\beta$-ol-20-one, and may be involved in regulating the concentrations of active $3 \beta$-hydroxysteroids in humans. Among substrates tested, catalytic efficiency of NRDRB1 towards benzil is the highest. To exclude artifactual loss of enzyme activity during purification, we also expressed human NRDRB1 and NRDR both in HEK293 cells, and in an in vitro translation system. These results similarly demonstrated a high capacity to reduce benzil to benzoin, but had no effect on further reduction to hydrobenzoin, suggesting that NRDR and its isoform NRDRB1 are only 


\section{Cellular Physiology Cell Physiol Biochem 2012;30:1371-1382

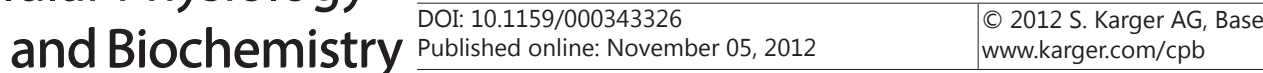 \\ Yan/Song/Liu et al.: Enhanced Enzymatic Activity of Alternatively Spliced Enzyme}

involved in the first reduction step of benzil. Quantitative enzymatic assays demonstrated that NRDRB1 exhibits much higher benzil reductive activity than NRDR. The high reactivity to benzil of NRDRB1 is significant from a pharmacological point of view, because benzil is one of the most widely used environmental diketones. It is used as a photosensitizer, organic synthesis intermediate, and adhesive, as well as a pesticide and especially in food packaging printing inks [27]. In vivo, benzil is not only a metabolite of the antiplatelet drug ditazol [28], but is also a specific competitive reversible inhibitor of human carboxylesterases [29].

Addition of benzil to different human cell lines revealed dose-dependent cytotoxicity. HL7702, HepG2, SKOV3, and Hela cells, all expressing NRDRB1, exhibit higher survival in the presence of benzil than the other four cell lines without detectable NRDRB1 expression. Over-expression of NRDRB1 in Ec109 cells enhances cell survival as well. Thus NRDRB1 confers resistance to benzil-induced cytotoxicity, as would be predicted from our results showing NRDRB1 has higher benzil reductive activity than its full-length enzyme. In terms of pharmacology, NRDRB1 may play a role in detoxifying benzil, as well as reactive $\alpha$-dicarbonyl compounds that are ingested.

Reactive $\alpha$-dicarbonyl compounds are generated during the course of metabolic processes, through oxidative stress in a variety of biological systems, or are present in dietary constituents [30]. When two carbonyl groups are adjacent on a carbon chain, the reactivity of each carbonyl group tends to be elevated, and those compounds with $\alpha$-dicarbonyl groups are cytotoxic, e.g. causing mitotic chromosome loss [31], or are prone to conversion into advanced glycation end-products [32]. The enzymatic detoxification of reactive $\alpha$-dicarbonyl compounds in eukaryotes is achieved by several members of the aldoketo reductase (AKR) and SDR families, including aldehyde reductase, aldose reductases, dihydrodiol dehydrogenase, DCXR, and sepiapterin reductase [33]. In our present study, the $\mathrm{k}_{\mathrm{cat}} / \mathrm{K}_{\mathrm{m}}$ value for benzil is over 600 -fold higher than that of sepiapterin reductase, which has been known as the most efficient mammalian benzil reductase [34]. We also find that $\alpha$-dicarbonyl compounds with aromatic rings are also excellent substrates for human NRDR, especially NRDRB1.

Alternative splicing is one of the most important mechanisms for generating a large number of mRNA and protein isoforms from the surprisingly small number of human genes. Unlike promoter activity, which primarily regulates the amount of transcripts, alternative splicing changes the structure of the transcripts and their encoded proteins, and can result in altered binding properties, intracellular localization, enzymatic activity, protein stability, and posttranslational modifications. The magnitude of the effects range from a complete loss of function or acquisition of a new function, to very subtle modulations, which are observed in the majority of cases reported [35-38]. In our present study, NRDRB1 and NRDR share similar substrate specificity. However, deletion of the amino acid segment encoded by exon 3 to form NRDRB1 enhances catalytic activity towards some substrates, especially $\alpha$-dicarbonyl compounds with aromatic rings. To the best of our knowledge, our study is the first to describe this phenomenon of the enzymes involved in biochemical reactions.

The DHRS4 gene cluster is located in a highly variable region [39], suspected to contain clues for the genomic evolution in man. Only one copy of the DHRS4 is found in mice, while the duplicated DHRS4L2 gene is found in primates, and a second DHRS4L1 duplication is present only in humans. Alternative splicing of DHRS4 becomes more complex as the complexity of its gene structure evolves, generating multiple protein isoforms that enable organisms to adjust to more complex environments and protect themselves from xenobiotic damage.

\section{Acknowledgements}

This work was supported by the National Basic Research Project of China (program 973, grant number 2010CD912503), and the National Natural Science Foundation of China (grant number 31071153 and 30970626 ). We thank Stanley L. Lin for comments on the manuscript. 


\section{Cellular Physiology Cell Physiol Biochem 2012;30:1371-1382 \begin{tabular}{l|l} 
DOI: 10.1159/000343326 & $\begin{array}{l}\text { O 2012 S. Karger AG, Basel } \\
\text { www.karger.com/cpb }\end{array}$ \\
and Biochemistry Published online: November 05, 2012 &
\end{tabular}

\section{References}

1 Jornvall H, Persson B, Krook M, Atrian S, Gonzalez-Duarte R, Jeffery J, Ghosh D: Short-chain dehydrogenases/ reductases (SDR). Biochemistry 1995;34:6003-6013.

2 Bray JE, Marsden BD, Oppermann U: The human short-chain dehydrogenase/reductase (SDR) superfamily: a bioinformatics summary. Chem Biol Interact 2009;17:99-109.

3 Filling C, Berndt KD, Benach J, Knapp S, Prozorovski T, Nordling E, Ladenstein R, Jornvall H, Oppermann $\mathrm{U}$ : Critical residues for structure and catalysis in short chain dehydrogenases /reductases. J Biol Chem 2002;277:25677-25684.

4 Huang DY, Ichikawa Y: Purification and characterization of a novel cytosolic NADP (H)-dependent retinol oxidoreductase from rabbit liver. Biochem Biophys Acta 1997;1338:47-59.

5 Lei Z, Chen W, Zhang M, Napoli JL: Reduction of all-trans-retinal inthe a liver peroxisome fraction by the short-chain dehydrogenase/reductase RRD: induction by the PPAR $\alpha$ ligand clofibrate. Biochemistry 2003;42:4190-4196.

6 Usami N, Ishikura S, Abe H, Nagano M, Uebuchi M, Kuniyasu A, Otagiri M, Nakayama H, Imamura Y, Hara A: Cloning, expression and tissue distribution of a tetrameric form of pig carbonyl reductase. Chem Biol Interact 2003;144:353-361.

7 Endo S, Matsunaga T, Nagano M, Abe H, Ishikura S, Imamura Y, Hara A: Characterization of an Oligomeric Carbonyl Reductase of Dog Liver: Its Identity with Peroxisomal Tetrameric Carbonyl Reductase. Biol Pharm Bull 2003;30:1787-1791.

8 Song XH, Liang B, Liu GF, Li R, Xie JP, Du K, Huang DY: Expression of a novel alternatively spliced variant of NADP(H)-dependent retinol dehydrogenase/reductase with deletion of exon 3 in cervical squamous carcinoma. Int J Cancer 2007;120:1618-1626.

9 Zhang Q Li Y, Liu G, Xu X, Song X, Liang B, Li R, Xie J, Du M, Xiao L, Huang D: Alternative transcription initiation and splicing variants of the DHRS4 gene cluster. Biosci Rep 2009;29:47-56.

10 Su ZJ, Zhang QX, Liu GF, Song XH, Li Q, Wang RJ, Chen HB, Xu XY, Sui XX, Huang DY: Bioinformatic analysis of the human DHRS4 gene cluster and a proposed mechanism for its transcriptional regulation. BMC Mol Biol 2010;11:43.

11 Du J, Huang DY, Liu GF, Wang GL, Xu XL, Wang B, Zhu L: cDNA cloning of a short isoform of human liver NADP (H)-dependent retinol dehydrogenase/reductase and analysis of its characteristics. Acta Genetica Sinica 2004;31:661-667.

12 Su Z, Li R, Song X, Liu G, Chang X, Huang D: Identification of a novel isoform of DHRS4 protein with nuclear localization signal. Gene 2012;494:161-167.

13 Sammeth M, Foissac S, Guigo R: A general definition and nomenclature for alternative splicing events. PLoS Comput Biol 2008;4:e1000147.

14 Wang ET, Sandberg R, Luo S, Khrebtukova I, Zhang L, Mayr C, Kingsmore SF, Schroth GP, Burge CB: Alternative isoform regulation in human tissue transcriptomes. Nature 2008;456:470-476.

15 Liu GF, Song XH, Liang B, Du K, Huang DY: Expression and antibody preparation of NADP-dependent retinol dehydrogenase/reductase. J China Med Univ 2006;35:227-229.

16 Maruyama R, Nishizawa M, Itoi Y, Ito S, Inoue M: Isolation and expression of a Bacillus cereus genencoding benzil reductase. Biotechnol Bioeng 2001;75:630-633.

17 Steven A, Lisa R, Govind R: Comparison of Trypan Blue Dye Exclusion and Fluorometric Assays for Mammalian Cell Viability Determinations. Bbtechnol Rag 1999;9:871-874.

18 Keller B, Volkmann A, Wilckens T, Moeller G, Adamski J: Bioinformatic identification and characterization of new members of short-chain dehydrogenase/reductase superfamily. Molecular and Cellular Endocrinology 2006;248:56-60.

19 Strömberg S, Björklund MG, Asplund C, Sköllermo A, Persson A, Wester K, Kampf C, Nilsson P, Andersson AC, Uhlen M, Kononen J, Ponten F, Asplund A: A high-throughput strategy for protein profiling in cell microarrays using automated image analysis. Proteomics 2007;7:2142-2150.

20 Matsunaga T, Endo S, Maeda S, Ishikura S, Tajima K, Tanaka N, Nakamura KT, Imamura Y, Hara A: Characterization of human DHRS4: An inducible short-chain dehydrogenase/reductase enzyme with 3ß-hydroxysteroid dehydrogenase activity. Arch Biochem Biophys 2008;477:339-347. 


\section{Cellular Physiology Cell Physiol Biochem 2012;30:1371-1382 \begin{tabular}{l|l} 
DOI: 10.1159/000343326 & $\begin{array}{l}\text { O 2012 S. Karger AG, Basel } \\
\text { www.karger.com/cpb }\end{array}$ \\
and Biochemistry Published online: November 05, 2012 &
\end{tabular}

21 Fransen M, Veldhoven P, Subramanii S: Identification of peroxisomal proteins by using M13 phage protein VI phage display: molecular evidence that mammalian peroxisomes contain a 2, 4-dienoyl-CoA reductase. Biochem J 1999;340:561-568.

22 Pellegrini S, Censini S, Guidotti S, Iacopetti P, Rocchiet M: A human short-chain dehydrogenase/reductase gene: structure, chromosomal localization, tissue expression and subcellular localization of its product. Biochim Biophys Acta 2002;1574:215-222.

23 Shafqat N, Shafqat J, Eissner G, Marschall H, Tryggvason K: Hep27, a member of the short-chain dehydrogenase/ reductase family, is an NADPH-dependent dicarbonyl reductase expressed in vascular endothelial tissue. Cell Mol Life Sci 2006;63:1205-1213.

24 Du K, Liu GF, Xie JP, Song XH, Li R, Liang B, Huang DY: A 27.368 kDa retinal reductase in New Zealand white rabbit liver cytosol encoded by the peroxisomal retinol dehydrogenase-reductase cDNA: purification and characterization of the enzyme. Biochem Cell Biol 2007;85:209-217.

25 Kisiela M, El-Hawari Y, Martin HJ, Maser E: Bioinformatic and biochemical characterization of DCXR and DHRS2/4 from Caenorhabditis elegans. Chem Biol Interact 2011;191:75-82.

26 Steckelbroeck S, Jin Y, Gopishetty S, Oyesanmi B, Penning TM: Human cytosolic 3 $\beta$-hydroxysteroid dehydrogenases of the aldo-keto reductase superfamily display significant $3 \beta$-hydroxysteroid dehydrogenase activity. J Biol Chem 2004;279:10784-10795.

27 Hardo S, Manfred E: Ketones; in Ullmann (eds): Encyclopedia of Industrial Chemistry. Wiley-VCH, Wienheim. doi:10.1002/14356007.a15_077.

28 Maurer H, Kleff I: On the metabolism of ditazole in man. Arzneimittel-forschung 1988;38:1843-1845.

29 Janice LH, Lyudmila T, Monika W, Carol CE, Mary KD, Philip MP: Intracellular inhibition of carboxylesterases by benzil: modulation of CPT-11 cytotoxicity. Mol Cancer Ther 2006;5:2281-2288.

30 Centeno JA, Fernandez GE, Gaya P, Tomillo J, Medina M, Nunez M: Volatile compounds in cheeses made from raw ewes' milk ripened with a lactic culture. J Dairy Res 2004;71:380-384.

31 Zimmermann FK, Mohr A: Formaldehyde, glyoxal, urethane, methyl carbamate, 2, 3-butanedione, 2, 3-hexanedione, ethyl acrylate, dibromoacetonitrile and 2-hydroxypropionitrile induce chromosome loss in Saccharomyces cerevisiae. Mutat Res 1992;270:151-166.

32 Monnier VM, Nagaraj RH, Portero OM, Glomb M, Elgawish AH, Sell DR, Friedlander MA: Structure of advanced Maillard reaction products and their pathological role. Nephrol Dial Transplant 1996;11:20-26.

33 Nakagawa J, Ishikura S, Asami J, Isaji T, Usami N, Hara A, Sakurai T, Tsuritani K, Oda K, Takahashi M, Yoshimoto M, Otsuka N, Kitamura K: Molecular characterization of mammalian dicarbonyl/L-xylulose reductase and its localization in kidney. J Biol Chem 2002;277:17883-17891.

34 Sueoka T, Katoh S: Sepiapterin reductase exhibits a NADPH-dependent dicarbonyl reductase activity. Biochem Biophys Res Commun 1984;118:859-866.

35 Stamm S, Ben-Ari S, Rafalska I, Tang Y, Zhang Z, Toiber D, Thanaraj TA, Soreq H: Function of alternative splicing. Gene 2005;344:1-20.

36 Keren H, Lev-Maor G, Ast G: Alternative splicing and evolution: diversification, exon definition and function. Nat Rev Genet 2010;11:345-355.

37 Wesley F, Malcolm AL, Matthew LH, Alice YC, Dennis JS: Alternative Splicing of Human Insulin-Degrading Enzyme Yields a Novel Isoform with a Decreased Ability To Degrade Insulin and Amyloid $\beta$-Protein. Biochemistry 2005;44:6513-6525.

38 Karen LM, Steve H, Mark M, Ann US, Shou W: The Human Aromatic l-Amino Acid Decarboxylase Gene Can Be Alternatively Spliced To Generate Unique Protein Isoforms. J Neurochem 1995;65:2409-2416.

39 Kidd JM, Cooper GM, Donahue WF, Hayden HS, Sampas N, Graves T, Hansen N, Teague B, Alkan C, Antonacci F, Haugen E, Zerr T, Yamada NA, Tsang P, Newman TL, Tüzün E, Cheng Z, Ebling HM, Tusneem N, David R, Gillett W, Phelps KA, Weaver M, Saranga D, Brand A, Tao W, Gustafson E, McKernan K, Chen L, Malig M, Smith JD, Korn JM, McCarroll SA, Altshuler DA, Peiffer DA, Dorschner M, Stamatoyannopoulos J, Schwartz D, Nickerson DA, Mullikin JC, Wilson RK, Bruhn L, Olson MV, Kaul R, Smith DR, Eichler EE: Mapping and sequencing of structural variation from eight human genomes. Nature 2008;453:56-64. 